\title{
Associations between prefrontal $\gamma$-aminobutyric acid concentration and the tryptophan hydroxylase isoform 2 gene, a panic disorder risk allele in women
}

\author{
Nora Preuss ${ }^{1}$, Basira Salehi ${ }^{2}$, Jan Willem van der Veen ${ }^{3}$, Jun Shen ${ }^{4}$, Wayne C. Drevets ${ }^{5,6}$, \\ Colin Hodgkinson ${ }^{7}$, David Goldman ${ }^{7}$ and Gregor Hasler ${ }^{2}$ \\ ${ }^{1}$ Department of Psychology, University of Bern, Switzerland \\ ${ }^{2}$ Psychiatric University Hospital, University of Bern, Switzerland \\ ${ }^{3}$ National Institute of Mental Health, Magnetic Resonance Spectroscopy Core, Bethesda, MD, USA \\ ${ }^{4}$ Department of Psychiatry, Yale School of Medicine, CT, USA \\ ${ }^{5}$ Laureate Institute for Brain Research, and University of Oklahoma College of Medicine, Tulsa, OK, USA \\ ${ }^{6}$ Janssen Research and Development, LLC of Johnson and Johnson, Inc., Titusville, NJ, USA \\ ${ }^{7}$ Laboratory of Neurogenetics, National Institute on Alcohol Abuse and Alcoholism, Bethesda, MD, USA
}

\begin{abstract}
Associations between the central serotonergic and $\gamma$-aminobutyric acid (GABA) systems play key roles in the prefrontal cortical regulation of emotion and cognition and in the pathophysiology and pharmacotherapy of highly prevalent psychiatric disorders. The goal of this study was to test the effects of common variants of the tryptophan hydroxylase isoform 2 (TPH2) gene on GABA concentration in the prefrontal cortex (PFC) using magnetic resonance spectroscopy. In this study involving 64 individuals, we examined the associations between prefrontal cortical GABA concentration and 12 single nucleotide polymorphisms (SNPs) spanning the TPH2 gene, including rs4570625 (-703 G/T SNP), a potentially functional TPH2 polymorphism that has been associated with decreased TPH2 mRNA expression and panic disorder. Our results revealed a significant association between increased GABA concentration in the PFC and the T-allele frequencies of two TPH2 SNPs, namely rs4570625 $(-703 \mathrm{G} / \mathrm{T})$ and $\mathrm{rs} 2129575(p \leqslant 0.0004)$ and the C-allele frequency of one TPH2 SNP, namely rs1386491 $(p=0.0003)$ in female subjects. We concluded that rs4570625 (-703 G/T), rs2129575 and rs1386491 play a significant role in GABAergic neurotransmission and may contribute to the sex-specific dysfunction of the GABAergic system in the PFC.
\end{abstract}

Received 5 November 2012; Reviewed 20 December 2012; Revised 28 January 2013; Accepted 24 February 2013; First published online 3 April 2013

Key words: GABA, genetics, magnetic resonance spectroscopy, single nucleotide polymorphisms, tryptophan hydroxylase 2 .

\section{Introduction}

The neurotransmitter serotonin (5-hydroxytryptamine; $5-\mathrm{HT})$ is one of the key modulators of the brain's circuits for emotion and adaptation to stress. Associations have been found between different neuropsychiatric disorders and the genes that modulate serotonergic neurotransmission, such as the TPH2 gene, which encodes for tryptophan hydroxylase

Address for correspondence: Professor Dr G. Hasler, Psychiatric University Hospital, Bolligenstrasse 111, 3000 Berne 60, Switzerland. Tel.: +41319309543 Fax: +41319309921

Email: g.hasler@bluewin.ch isoform 2, an enzyme exclusively expressed in the brain (Maron et al., 2007; Gutknecht et al., 2009; Roche and McKeon, 2009). Tryptophan hydroxylase, which is the rate-limiting enzyme in 5-HT synthesis, catalyses the hydroxylation of tryptophan. One of the major target structures of the central serotonergic system is the prefrontal cortex (PFC). Selective 5-HT reuptake inhibitors (SSRIs) can significantly increase brain $\gamma$-aminobutyric acid (GABA) concentration (Bhagwagar et al., 2004); suggesting that altering 5-HT concentration will have a direct impact on GABA concentration. However, it should be noted that Bhagwagar et al. (2004) observed GABA concentration in the occipital cortex. Evidence regarding 
possible effects of SSRIs on GABA levels in the PFC is still missing. Glutamatergic pyramidal neurons and GABA interneurons are the two major neuronal populations in the PFC. GABAergic interneurons exert powerful inhibitory control over excitatory efferent projections from the PFC (Feng et al., 2001). The main effect of physiologically released 5-HT on these PFC projections is inhibitory (Puig et al., 2005). Serotonergic axons synapse predominantly on interneurons (Smiley and Goldman-Rakic, 1996), and 5-HT can strongly modulate GABA-mediated inhibitory neurotransmission (Ciranna, 2006). The psychiatric conditions associated with impaired serotonergic neurotransmission are also associated with a dysfunctional GABA system. Schizophrenia, depression and anxiety have been associated with reduced cortical GABA concentration (Akbarian et al., 1995; Sanacora et al., 1999; Goddard et al., 2001; Hasler et al., 2007, 2010). Specifically, anxiety disorders have been associated with low GABA concentration in the PFC (Goddard et al., 2001; Hasler, 2010; Hasler et al., 2010). Moreover, the GABA system is the target of novel antidepressants and mood-stabilizing treatments (Krystal et al., 2002). SSRIs that produce antidepressant and anxiolytic effects have been shown to increase the firing rates of GABA interneurons (Zhong and Yan, 2011) and, as mentioned earlier, increase brain GABA concentration (Bhagwagar et al., 2004). Taken together, these data suggest that the 5 -HT $\times$ GABA interactions within the PFC play a key role in the prefrontal cortical regulation of emotion and cognition and in the pathophysiology and pharmacotherapy of highly prevalent psychiatric disorders.

Human variants of TPH2 have been related to anxiety-related traits (Waider et al., 2011), amygdala reactivity (Brown et al., 2005; Canli et al., 2005) and psychiatric disorders (Walitza et al., 2005; Mossner et al., 2006b; Kim et al., 2009). However, the molecular pathways that are affected by the TPH 2 variants and which result in the risk of psychiatric disorders have not yet been elucidated. Low cortical GABA concentrations have been proposed as the most promising imaging endophenotype in mood and anxiety disorders (Hasler and Northoff, 2011).

We hypothesized that variations within the TPH2 gene significantly influence prefrontal cortical GABA concentration, as determined by magnetic resonance spectroscopy (MRS). We examined the associations between GABA concentration in the medial PFC and 12 single nucleotide polymorphisms (SNPs) spanning the TPH2 gene, including rs4570625 (-703 G/T SNP). Moreover, based on sex differences in 5-HT (5-HT transporter and $5-\mathrm{HT}_{1 \mathrm{~A}}$ and $5-\mathrm{HT}_{2 \mathrm{~A}}$ receptors) and brain GABA concentrations (Cosgrove et al., 2007), we examined the associations in male and female subjects separately. Kim et al. (2009) showed a significant association of rs4570625 with panic disorder (PD) in women. This SNP is potentially functional given recent evidence that the $G$ allele is associated with decreased TPH2 mRNA expression relative to the $\mathrm{T}$ allele (Lin et al., 2007; Chen et al., 2008). The samples were genotyped with a haplotype capture array developed and described previously (Hodgkinson et al., 2008). Conceivably, our results may help to elucidate the molecular mechanisms that influence the serotonergic regulation of GABAergic transmission within the PFC.

\section{Method \\ Participants}

Volunteers were recruited through newspaper advertisements and posters displayed on the National Institutes of Health, Bethesda campus under a protocol that was approved by the Institutional Review Board of the National Institute of Mental Health. All participants were evaluated for psychiatric diagnoses by an unstructured clinical interview with a psychiatrist as well as with a Structured Clinical Interview of the Diagnostic and Statistical Manual of Mental Disorders-IV and the Structured Interview Guides for the Hamilton Depression Rating Scale and Montgomery-Åsberg Depression Rating Scale. The clinical evaluation involved a physical examination, electrocardiography and laboratory tests, including kidney and liver function tests, hematologic profiling, thyroid function test, urinalysis and toxicology (drug screen). Exclusion criteria were current medical or neurological disorders, pregnancy, smoking and/or substance abuse. Patients were not under psychotropic medication for at least $4 \mathrm{wk}$ prior to scanning. All participants gave informed consent and the study was approved by the Combined Neuroscience Institutional Review Board at the National Institutes of Health (Hasler et al., 2007).

The study population consisted of 64 individuals from the following four diagnostic groups: healthy controls $[n=20 ; 15$ women; aged (mean \pm S.D.) $36.9 \pm$ $13.8 \mathrm{yr}]$; individuals with a current episode of major depressive disorder ( $n=19 ; 12$ women; aged $31.5 \pm 9 \mathrm{yr}$ ); individuals with remitted major depressive disorder ( $n=16 ; 12$ women; aged $40.8 \pm 11.7 \mathrm{yr}$ ); individuals with PD ( $n=9$; 8 women; aged $33.8 \pm 12.8 \mathrm{yr}$ ). In individuals with $\mathrm{PD}$, mean score ( \pm S.D.) for the Panic Disorder Severity Scale was 7.15 \pm 3.16 , for the Panic Symptom Scale $18.5 \pm 6.02$ and for the Hamilton Anxiety Scale 10.08 \pm 6.42 . 


\section{Magnetic resonance spectroscopy}

We used in vivo proton MRS to assess the cerebral GABA concentration. Participants underwent scanning in a single session with a 3-T whole-body scanner and a transmit-receive head coil (General Electric Medical Systems, USA) that was capable of providing a homogeneous radio frequency field and spectroscopic measurements of the PFC.

Proton MRS spectra were acquired in a voxel $(3 \times 3 \times$ $2 \mathrm{~cm}^{3}$ ) positioned with the posterior edge $1 \mathrm{~mm}$ anterior to the rostrum of the corpus callosum and centred on the midline in the horizontal plane and on the bicommissural line in the sagittal plane. This voxel included portions of the perigenual anterior cingulate cortex and the adjacent frontal polar cortex (i.e. portions of Brodmann areas 24, 32 and 10; Hasler et al., 2010).

The unedited part of an interleaved positionresolved spectroscopy sequence-based $\mathrm{J}$ editing method (Sailasuta et al., 2001; Hasler et al., 2007, 2010) was used to measure the concentrations of $\mathrm{N}$-acetylaspartate, choline and creatine metabolites, and the spectrum resulting from the subtraction of the unedited and the edited spectra was used to specifically measure the GABA concentration. Echo time for this sequence was set to $68 \mathrm{~ms}$ and a single scan consisted of 1024 averages at a repetition time of $1.5 \mathrm{~s}$ for a total scan time of $25.6 \mathrm{~min}$. The concentrations of GABA, which were referenced to the concentration of creatine, were expressed as $\mathrm{mmol} / \mathrm{l}$ (mM). In order to reference the spectra to a quantitative standard, the creatine concentration was set to $7.1 \mathrm{~mm}$, which is the average creatine concentration in the grey and white matter reported in the literature. This conventional creatine referencing method, which is well suited for this study because of the extremely low turnover rate of total creatine in the brain (Wyss and Kaddurah-Daouk, 2000), has been validated and described previously (Shen et al., 2002; Sanacora et al., 2003). In the current study, only the GABA:creatine ratios were measured. Since the brain metabolism of creatine is unrelated to tryptophan hydroxylase or variations in the TPH2 gene, we believe that it is safe to assume that creatine is not affected by variations in TPH2 SNPs. Interleaved acquisition and careful in vivo and in vitro quality control procedures were employed in order to ensure the quality of the data. No subtraction errors were detected between the edited and unedited scans.

\section{Genotyping}

Peripheral blood was drawn from all 64 participants and DNA was extracted with standard procedures.
Samples were genotyped with an addiction array, which was developed by Hodgkinson et al. (2008). This array was developed in order to include a panel of markers that are able to provide full haplotype information for the candidate genes of interest in addictive and mood disorders. Our array included the following 12 SNPs that span the TPH2 gene: rs4570625; rs10748185; rs2129575; rs1386488; rs1843809; rs1386496; rs2171363; rs1386491; rs6582078; rs1352250; rs1487275; rs1386483. For all 64 participants, information was available on ancestry informative markers (AIMs). The ancestry of each subject was evaluated separately in the context of the worldwide genetic factor structure. As a result, the AIMs were derived in a consistent way in order to reflect any of the major worldwide ancestry factors. We used 186 AIMs to evaluate these individuals for the population stratification of GABA concentration. Each AIM was a SNP of a known allele frequency in HapMap reference populations and a 6-factor solution was used to estimate the ancestry with Structure version 2.0 (Falush et al., 2003), as described previously (Zhou and Wang, 2008).

\section{Statistics}

Statistical analyses were performed with the Statistical Package for the Social Sciences (SPSS) for Mac (version 19.0; IBM Corporation, USA). Allele frequencies are provided in Table 1 . We calculated pairwise linkage disequilibrium (LD) between the SNPs with the SNP Analyser 1.2 (Istech Corp., Korea). In order to describe $\mathrm{LD}$, we used the absolute value of $D^{\prime}$. $D^{\prime}$ values and statistical significance are provided in Table 2 . Multiple linear regressions for the number of minor alleles were performed in order to examine the association between GABA concentration and genotype at each SNP. An additive genetic model was tested by recoding the three SNP genotypes as 0 for the homozygote of the common allele, 1 for the heterozygote and 2 for the homozygote of the uncommon allele. In order to keep type-I error at a rate $<5 \%$, we computed the Šidák-corrected significance threshold for multiple testing of SNPs in LD with SNPSpD (Šidák, 1967; Nyholt, 2004):

$\alpha_{p}=1-\left(1-\alpha_{e}\right)^{1 / M_{\text {effLi }}}$

The number of independent SNPs $\left(M_{\text {effLi }}\right)$ was six and the $M_{\text {effLi }}$ Šidák correction was 0.008 . $M_{\text {effLi }}$ was calculated using the following equation:

$$
\begin{aligned}
M_{\text {effLi }} & =\sum_{i=1}^{M} f\left(\left|\lambda_{i}\right|\right) \\
f(x) & =I(x \geqslant 1)+(x-\lfloor x\rfloor), \quad x \geqslant 0
\end{aligned}
$$


Table 1. Descriptive statistics of the 12 single nuclear polymorphisms (SNP)

\begin{tabular}{lllllll}
\hline & SNP & Chromosome & Gene & Location & Polymorphism & Allele frequency \\
\hline SNP1 & rs4570625 & 12 & TPH2 & 70618190 & G/T & $0.73 / 0.27$ \\
SNP2 & rs10748185 & 12 & TPH2 & 70622122 & A/G & $0.42 / 0.58$ \\
SNP3 & rs2129575 & 12 & TPH2 & 70626340 & G/T & $0.71 / 0.29$ \\
SNP4 & rs1386488 & 12 & TPH2 & 70630885 & A/C & $0.79 / 0.21$ \\
SNP5 & rs1843809 & 12 & TPH2 & 70634965 & G/T & $0.18 / 0.82$ \\
SNP6 & rs1386496 & 12 & $T P H 2$ & 70637057 & C/T & $0.16 / 0.84$ \\
SNP7 & rs2171363 & 12 & $T P H 2$ & 70646531 & C/T & $0.47 / 0.53$ \\
SNP8 & rs1386491 & 12 & $T P H 2$ & 70648645 & C/G & $0.22 / 0.78$ \\
SNP9 & rs6582078 & 12 & $T P H 2$ & 70661158 & G/T & $0.45 / 0.55$ \\
SNP10 & rs1352250 & 12 & $T P H 2$ & 70684051 & A/G & $0.52 / 0.48$ \\
SNP11 & rs1487275 & 12 & $T P H 2$ & 70696559 & G/T & $0.27 / 0.73$ \\
SNP12 & rs1386483 & 12 & $T P H 2$ & 70698761 & A/G & $0.6 / 0.4$ \\
\hline
\end{tabular}

Table 2. $D^{\prime}$ and $p$ values for all combinations of TPH2 single nuclear polymorphisms (SNP)

\begin{tabular}{lllllllllllll}
\hline & SNP1 & SNP2 & SNP3 & SNP4 & SNP5 & SNP6 & SNP7 & SNP8 & SNP9 & SNP10 & SNP11 & SNP12 \\
\hline SNP1 & & $<0.0001$ & $<0.0001$ & 0.218 & 0.173 & 0.172 & $<0.0001$ & $<0.0001$ & $<0.0001$ & $<0.0001$ & 0.332 & $<0.0001$ \\
SNP2 & 1 & & $<0.0001$ & $<0.0001$ & $<0.0001$ & $<0.0001$ & $<0.0001$ & $<0.0001$ & $<0.0001$ & $<0.0001$ & $<0.0001$ & $<0.0001$ \\
SNP3 & 0.913 & 0.889 & & 0.368 & 0.24 & 0.098 & $<0.0001$ & $<0.0001$ & $<0.0001$ & $<0.0001$ & 0.031 & $<0.0001$ \\
SNP4 & 0.344 & 0.84 & 0.239 & & $<0.0001$ & $<0.0001$ & $<0.0001$ & $<0.0001$ & $<0.0001$ & $<0.0001$ & $<0.0001$ & 0.017 \\
SNP5 & 0.421 & 0.83 & 0.343 & 0.827 & & $<0.0001$ & $<0.0001$ & $<0.0001$ & $<0.0001$ & $<0.0001$ & $<0.0001$ & $<0.0001$ \\
SNP6 & 0.458 & 0.772 & 0.52 & 0.933 & 1 & & $<0.0001$ & $<0.0001$ & $<0.0001$ & $<0.0001$ & $<0.0001$ & 0.03 \\
SNP7 & 1 & 0.846 & 1 & 0.743 & 1 & 1 & & $<0.0001$ & $<0.0001$ & $<0.0001$ & $<0.0001$ & $<0.0001$ \\
SNP8 & 0.785 & 1 & 0.889 & 1 & 1 & 1 & 1 & & $<0.0001$ & $<0.0001$ & 0.041 & 0.871 \\
SNP9 & 0.782 & 0.842 & 0.876 & 0.814 & 0.767 & 0.869 & 0.957 & 1 & & $<0.0001$ & $<0.0001$ & $<0.0001$ \\
SNP10 & 0.839 & 0.761 & 0.932 & 0.588 & 0.744 & 0.68 & 0.884 & 0.896 & 0.892 & & $<0.0001$ & $<0.0001$ \\
SNP11 & 0.086 & 0.503 & 0.189 & 0.325 & 0.492 & 0.484 & 0.798 & 0.201 & 0.645 & 0.928 & \\
SNP12 & 0.459 & 0.471 & 0.403 & 0.311 & 0.449 & 0.346 & 0.791 & 0.033 & 0.471 & 0.781 & 0.831 & $<0.0001$ \\
\hline
\end{tabular}

where $\lambda_{i}$ is the eigenvalue of $c$ identical tests, $I(x \geqslant 1)$ is the indicator function and $\lfloor x\rfloor$ is the floor function (for detailed information see $\mathrm{Li}$ and Ji, 2005). Possible effects of gender, age, diagnosis and ancestry on GABA level were calculated with a stepwise linear regression.

\section{Results}

We found significant associations between prefrontal GABA concentration and allele frequencies for the rs4570625, rs2129575 and rs1386491 SNPs $(p \leqslant 0.008$; Table 3). Rs4570625 (G/T polymorphism), rs2129575 (G/T polymorphism) and rs1386492 (C/G polymorphism) significantly predicted GABA concentration. GABA levels increased with the number of $\mathrm{T}$ or $\mathrm{C}$ alleles.
There were no significant associations between gender, age or psychiatric disorder with GABA concentration ( $p>0.47$, Fig. 1). Additionally, none of the ancestry factors predicted GABA level $(p>0.1)$.

Number of participants per genotype for rs4570625, rs2129575 and rs1386492 is presented in Table 4. Due to the small number of participants with the homozygote of the uncommon allele, participants were divided into two groups based on genotype for both rs4570625 and rs2129575 for further analysis (see also Canli et al., 2005). One group consisted of either one or two copies of the $\mathrm{T}$ allele (T-carriers) and the other group consisted of non-T-carriers. Similar groups were built for rs1386492. One group consisted of either one or two copies of the $\mathrm{C}$ allele (C-carriers) and the other group consisted of non-C-carriers.

Given the important sex differences in the central 5-HT and GABA systems (Hasler and Northoff, 2011), 


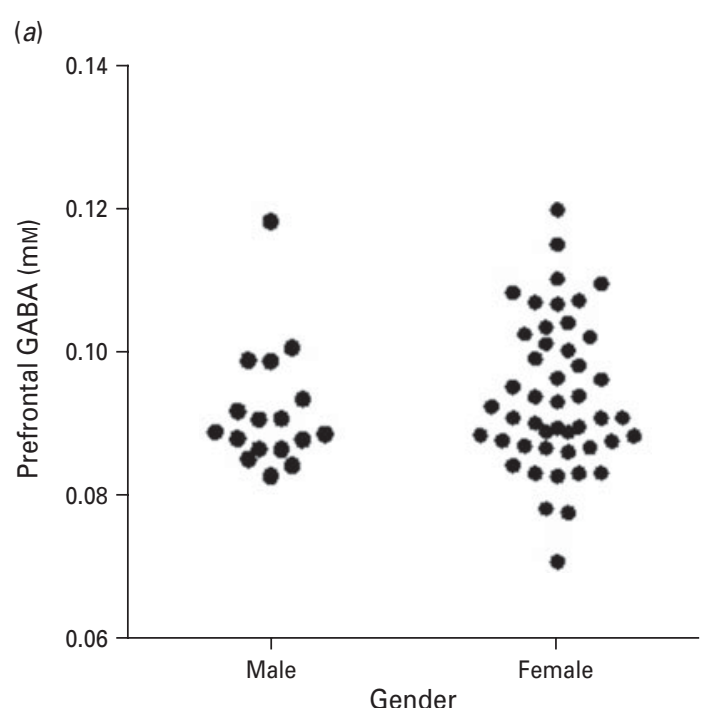

(b)
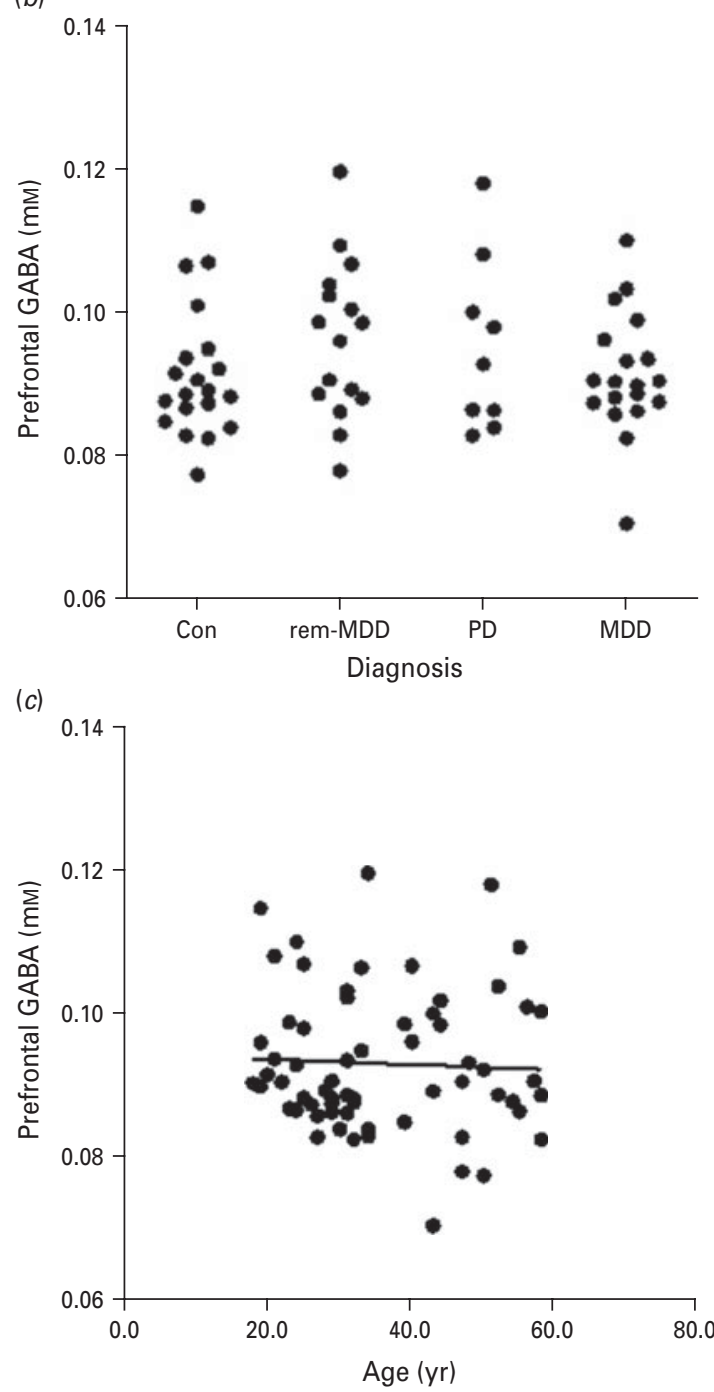

Fig. 1. Relationships between prefrontal cortical $\gamma$-aminobutyric acid (GABA) concentrations and (a) gender,
Table 3. Association analysis of polymorphisms within tryptophan hydroxylase isoform 2 (TPH2) and prefrontal $\gamma$-aminobutyric acid (GABA) levels

\begin{tabular}{|c|c|c|}
\hline Chr/Gene & SNP & $\begin{array}{l}\text { Linear regression with GABA } \\
\text { concentration }(n=64)\end{array}$ \\
\hline TPH2 & $\begin{array}{l}\text { rs4570625 } \\
\text { rs10748185 } \\
\text { rs2129575 } \\
\text { rs1386488 } \\
\text { rs1843809 } \\
\text { rs1386496 } \\
\text { rs2171363 } \\
\text { rs1386491 } \\
\text { rs6582078 } \\
\text { rs1352250 } \\
\text { rs1487275 } \\
\text { rs1386483 }\end{array}$ & $\begin{array}{l}B=0.007 ; p=0.002 ; r^{2}=0.14 \\
B=0.002 ; p=0.21 ; r^{2}=0.025 \\
B=0.007 ; p=0.001 ; r^{2}=0.159 \\
B=-0.002 ; p=0.45 ; r^{2}=0.009 \\
B=-0.001 ; p=0.76 ; r^{2}=0.002 \\
B=-0.001 ; p=0.59 ; r^{2}=0.005 \\
B=-0.001 ; p=0.65 ; r^{2}=0.003 \\
B=0.006 ; p=0.008 ; r^{2}=0.109 \\
B=0.003 ; p=0.13 ; r^{2}=0.036 \\
B=-0.003 ; p=0.15 ; r^{2}=0.032 \\
B=0.000 ; p=0.86 ; r^{2}=0.000 \\
B=0.000 ; p=0.86 ; r^{2}=0.000\end{array}$ \\
\hline
\end{tabular}

The effects of seven single nuclear polymorphisms (SNPs) were tested in 64 individuals by the linear regression of minor allele occurrences on the magnetic resonance spectroscopy-determined in vivo GABA concentrations. Significant association of the three SNPs, rs4570625, rs2129575 and rs1386491 with the GABA levels survived Bonferroni's correction for multiple testing.

we tested the associations in male and female participants separately. In an attempt to examine the possible interactions of gender and genotype, we used the SPSS macro Modprobe (Hayes and Matthes, 2009). The dependent variable was GABA level, the focal predictor was the respective genotype (rs4570625, rs2129575 and rs1386491) and the moderator variable was gender.

The overall fit of the first model (rs4570625) was highly significant $\left(R^{2}=0.2, F=5.06\right.$, d.f. $1=3$, d.f. $2=60$, $p=0.003)$. Including the genotype $\times$ gender interaction $(b=0.013$, S.E. $=0.005, t=2.59, p=0.012)$ increased $R^{2}$ significantly $\left(\Delta R^{2}=0.1, F=6.69, p=0.01\right)$. The moderator variable, gender, did not predict GABA level $(b=-0.005$, s.E. $=0.004, t=-1.23, p=0.22)$. There was a tendency for genotype to predict GABA level $(b=-0.017$, s.E. $=0.009, t=-1.83, p=0.07)$. Interestingly, the conditional effects of the focal predictor revealed a highly significant effect of genotype on GABA level in female participants $(b=0.01$, S.E. $=0.003, t=3.72$, $p=0.0004)$ but not in male participants $(b=-0.004$, S.E. $=0.005, t=-0.8, p=0.43)$. The $\mathrm{T}$ allele of rs 4570625

(b) psychiatric diagnosis and (c) age. None of these variables was associated significantly with GABA levels. Con, healthy controls; MDD, major depressive disorder; rem-MDD, remitted MDD; PD, panic disorder. 
Table 4. Number of participants depending on genotype (GG, GT, TT, CG, CC) and gender for the single nuclear polymorphisms (SNP) rs4570625, rs2129575 and rs1386491

\begin{tabular}{llrcc}
\hline SNP & Gender & GG & GT & TT \\
\hline rs4570625 & Male & 7 & 10 & 0 \\
& Female & 24 & 22 & 1 \\
& Total & 31 & 32 & 1 \\
rs2129575 & Male & 6 & 11 & 0 \\
& Female & 24 & 20 & 3 \\
& Total & 30 & 31 & 3 \\
& & GG & CG & CC \\
& & 8 & 7 & 2 \\
rs1386491 & Male & 31 & 15 & 1 \\
& Female & 39 & 22 & 3 \\
& Total & & &
\end{tabular}

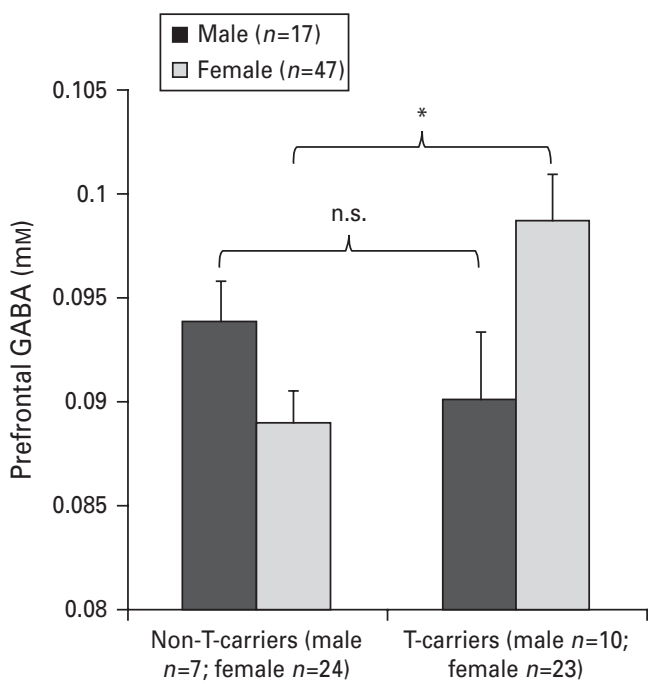

Fig. 2. Association between $\gamma$-aminobutyric acid (GABA) levels and the single nucleotide polymorphism rs4570625 that was analysed separately for male and female subjects. The association between genotype and GABA level became significant for female subjects $\left({ }^{*} p=0.0004\right)$ but not for male subjects (n.s., $p=0.43$ ).

was associated with higher prefrontal GABA concentration in women (Fig. 2).

The overall fit of the second model (rs2129575) was highly significant $\left(R^{2}=0.26, F=6.96\right.$, d.f. $1=3$, d.f. $2=60$, $p=0.0004)$. Including the significant genotype $\times$ gender interaction $(b=0.016$, s.E. $=0.005, t=3.18, p=0.002)$ significantly improved $R^{2}\left(\Delta R^{2}=0.12, F=10.09, p=0.002\right)$. Genotype $(b=-0.021$, S.E. $=0.009, t=-2.32, p=0.023)$ significantly predicted GABA level but gender $(b=-0.007$, S.E. $=0.004, t=-1.67, p=0.1)$ did not. The conditional effects of the focal predictor depending

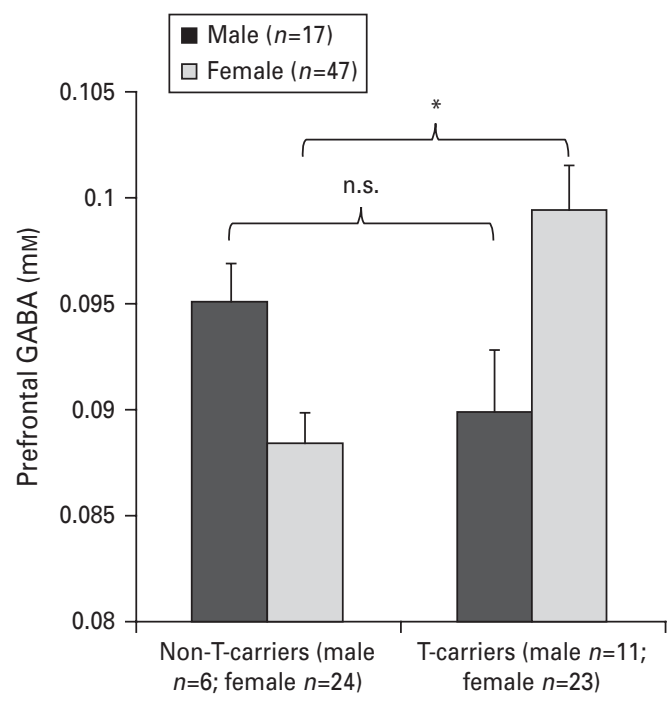

Fig. 3. Association between $\gamma$-aminobutyric acid (GABA) levels and the single nucleotide polymorphism rs2129575 that was analysed separately for male and female subjects. The association between genotype and GABA level became significant for female subjects $\left({ }^{*} p=0.0001\right)$ but not for male subjects (n.s., $p=0.25$ )

on the values of the moderator variable revealed that the effects for genotype became significant for female participants $(b=0.01$, S.E. $=0.003, t=4.33, p=0.0001)$ but not for male participants $(b=-0.005$, S.E. $=0.004$, $t=-1.17, p=0.25)$. The T allele of rs2129575 was associated with increased prefrontal GABA concentration in women (Fig. 3).

The overall fit of the third model (rs1386491) was highly significant $\left(R^{2}=0.21, F=5.16\right.$, d.f. $1=3$, d.f. $2=60$, $p=0.003)$. Including the genotype $\times$ gender interaction $(b=0.01, \quad$ S.E. $=0.005, \quad t=2.41, \quad p=0.004)$ significantly improved $R^{2}\left(\Delta R^{2}=0.08, F=5.83, p=0.02\right)$. Genotype $(b=-0.015$, s.E. $=0.009, t=-1.57, p=0.12)$ and gender $(b=-0.003$, s.E. $=0.004, t=-0.7, p=0.49)$ had no effect on prefrontal GABA concentration. The conditional effects of the focal predictor genotype depending on the values of the moderator variable, gender, revealed that the effects for genotype became significant for female participants $(b=0.01$, S.E. $=0.003, t=3.82$, $p=0.0003)$ but not for male participants $(b=-0.002$, S.E. $=0.004, t=-0.44, p=0.66$; Fig. 4). The $\mathrm{C}$ allele of rs1386491 was associated with higher prefrontal GABA concentration in female participants.

\section{Discussion}

To our knowledge, this is the first assessment of associations between genetic variations within the brainspecific 5-HT-synthesizing enzyme gene TPH2 and 


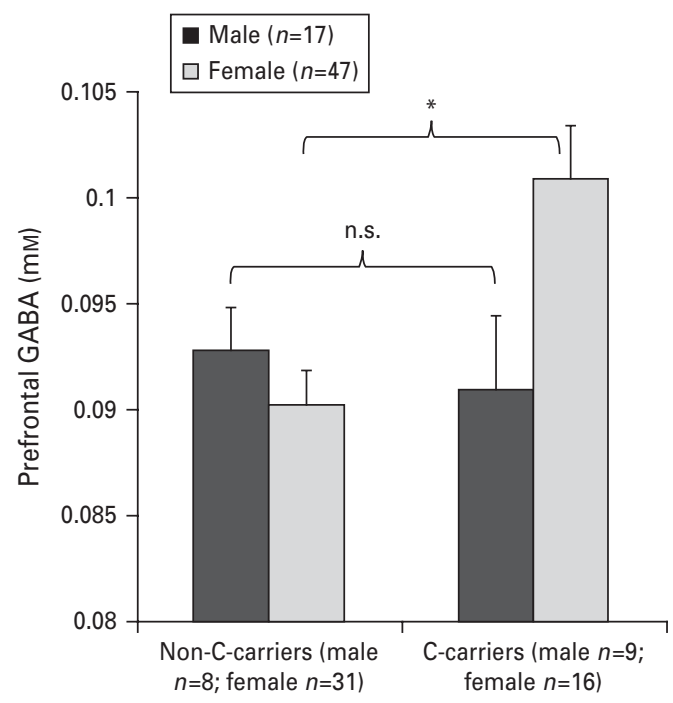

Fig. 4. Association between $\gamma$-aminobutyric acid (GABA) levels and the single nucleotide polymorphism rs1386491 that was analysed separately for male and female subjects. The association between genotype and GABA level became significant for female subjects $\left({ }^{*} p=0.0003\right.$ ) but not for male subjects (n.s., $p=0.66$ )

PFC GABA concentrations. Our results revealed a significant association between the T-allele frequencies of two TPH2 SNPs [rs4570625 (-703 G/T) and rs2129575] and the C-allele frequency of one SNP (rs1386491) and increased GABA concentration in the PFC in female subjects. Given the evidence for an association between $-703 \mathrm{G} / \mathrm{T}$ and TPH 2 mRNA expression, the findings of this study suggest that this polymorphism exerts a functional effect on GABAergic neurotransmission in the PFC and that this may contribute to deficits in GABAergic system function that have been reported in patients with PD and other highly prevalent psychiatric conditions.

The T allele of the SNP rs4570625 (-703 G/T) has been associated with different psychopathological disorders, such as schizophrenia (Fang et al., 2011), suicidal behaviour in major depression (Yoon and Kim, 2009), personality disorder and attention deficit/hyperactivity disorder (Jacob et al., 2010). Furthermore, the T allele of the SNP rs4570625 (-703 $\mathrm{G} / \mathrm{T}$ ) has also been associated with low anxiety levels (Gutknecht et al., 2007; Reuter et al., 2007). Functional MRS imaging studies have shown relatively increased haemodynamic activity in the amygdala in response to negatively and positively valenced emotional stimuli in T-allele carriers than in G-allele homozygous individuals (Brown et al., 2005; Canli et al., 2005). It is conceivable that this differential haemodynamic responsiveness of the amygdala to emotional stimuli is related to the differential GABA concentrations in the PFC. Studies in humans and experimental animals have shown that neural activity in some medial PFC regions reduces outflow from the central nucleus of the amygdala (Quirk et al., 2003; Phelps et al., 2004; Sotres-Bayon and Quirk, 2010). The intra-synaptic GABA concentration is regulated in part by the intracellular GABA concentration (Jackson et al., 2000). Therefore, higher MRSdetermined GABA concentrations in both intracellular and extracellular compartments would most likely be associated with increased GABAergic transmission within the medial PFC. If so, this higher inhibitory transmission within the medial PFC might reduce efferent prefrontal cortical transmission to the amygdala, thereby diminishing the cortical modulation of the amygdala response to emotional stimuli and potentially producing effects like those observed (Brown et al., 2005; Canli et al., 2005).

The T allele of rs4570625 $(-703 \mathrm{G} / \mathrm{T})$ is associated with increased TPH2 mRNA expression in the raphe nuclei where it catalyses the rate-limiting step in 5-HT synthesis (Lim et al., 2007). Thus, the T allele presence may result in increased serotonergic neurotransmission to the $\mathrm{PFC}$, which receives serotonergic projections from the dorsal raphe nucleus. Serotonergic axons synapse predominantly on GABAergic interneurons in the PFC (Smiley and Goldman-Rakic, 1996) and the higher 5-HT transmission associated with the administration of SSRIs increases both the firing rates of GABAergic interneurons (Zhong and Yan, 2011) and the brain GABA concentrations (Bhagwagar et al., 2004). Thus, the association between the $\mathrm{T}$ allele and the increased TPH 2 mRNA expression in the raphe nuclei suggests a mechanism by which this variant may result in the higher GABA concentrations found herein.

Several studies have shown that genetic variations in TPH2 polymorphisms are associated with a number of psychiatric disorders such as major depression, suicide, anxiety and attention deficit/hyperactivity disorders (De Luca et al., 2004, 2005; Mouri et al., 2009; Must et al., 2009). It has been hypothesized that dysfunction within the serotonergic system plays a major role in anxiety disorders and that both SSRIs and monoamine oxidase inhibitors show antipanic, anxiolytic and antidepressant effects in such disorders. Unfortunately, we did not assess anxiety levels in subjects with past or present major depressive disorder and healthy controls. However, it is important to note that Hasler et al. (2009) did not find any relationship between PFC GABA concentration and current anxiety levels. 
A recent study could show that genetic variations (including rs2129575) in the TPH2 gene may partly account for variations in 5-HT synthesis in the orbitofrontal cortex (Booij et al., 2012). Jacobsen et al. (2012) reported reduced basal and stimulated levels of extracellular 5-HT and increased frontal 5- $\mathrm{HT}_{2 \mathrm{~A}}$ receptors in $\mathrm{TPH} 2 \mathrm{R} 439 \mathrm{H}$ knockin mice. However, they did not find changes in basal extracellular prefrontal GABA levels. Interestingly, a recent study in mice found that brain 5-HT deficiency, resulting from TPH2 inactivation, differentially affects GABAergic systems in limbic regions (Waider et al., 2012). Moreover, genetic studies have revealed an association between variations in the TPH2 gene and PD. Although Mössner et al. (2006a) found no association between the two SNPs [rs4570625 (-703 G/T) and rs4565946] of the $\mathrm{TPH} 2$ gene and PD in a population from Germany, Kim et al. (2009) found a significantly lower frequency of the T allele of the rs4570625 (-703 G/T) polymorphism in PD patients than in healthy controls. Both these previous studies focused on a single SNP and did not examine the effects of genetic variations along the entire length of the TPH2 gene.

The present study revealed that the $C$ allele of rs1386491 was associated with higher prefrontal GABA concentration. Only a few studies have examined the association between psychiatric disorders and rs1386491. One study reported an association between the TPH2 risk haplotype GGTG (including rs1386491) and borderline personality disorder, suicidal behaviour and aggression score (PerezRodriguez et al., 2010). The risk haplotype GGTG (rs2171363, rs1386491, rs6582078 and rs1352250) was first identified by Zhou et al. (2005). Other studies could not show an association between the TPH2 gene (including rs1386491) and suicidal behaviour (Mouri et al., 2009; Must et al., 2009).

One limitation of the present study needs to be mentioned. We did not find any differences in GABA concentration between the control subjects and the other diagnostic groups, which may be because of the small sample sizes of each diagnostic group (Hasler et al., 2009). Nevertheless, the results showed a strong relationship between variations of the TPH2 gene and prefrontal GABA concentration. This may confirm the importance of examining molecular mechanisms rather than behavioural phenotypes, given the relatively long passage from genes and gene products to psychopathology and the complex and heterogeneous genetic underpinnings of psychological traits (Hasler and Northoff, 2011).

Recent studies have suggested sex differences in the GABA systems and in the neurotransmission of 5-HT
(Cosgrove et al., 2007). These molecular differences have also been linked to the pathophysiology of anxiety disorders, such as PD. PD is more prevalent in women than in men (Weissman et al., 1997; Grant et al., 2006). While male PD patients showed abnormal 5-HT transporter availability in various brain regions, there was no such abnormality in female PD patients (Maron et al., 2011). Furthermore, treatment with the SSRI sertraline showed superior efficacy in women than in men with PD (Clayton et al., 2006). Finally, previous studies have found important sex differences in the association between TPH2 variants and PD (Maron et al., 2007; Kim et al., 2009). In particular, Kim et al. (2009) have found a significant association with rs4570625 in the female subgroup only. These results are in line with our results that showed strong associations between the three TPH2 SNPs [rs4570625 (-703 G/T), rs2126575 and rs1386491] with prefrontal GABA concentration in female study participants.

One downside to the present study was the relatively low number of male subjects, which may have been a result of the heterogeneous mix of patient groups and healthy subjects. However, it is important to keep in mind that the association between the TPH2 gene and prefrontal GABA level became stronger when male subjects were excluded and that the descriptive data for male subjects goes in the reverse direction than for female subjects. A power analysis revealed that for rs4570625 a minimum of 297 male participants would have been required to have an $80 \%$ chance to detect a significant effect of genotype on GABA. Furthermore, for rs2129575 a minimum of 187 and for rs1386491 a minimum of 1263 male subjects would have been required. Hence, we cannot exclude that a higher number of male participants might have led to a reversed main effect in males or may have cancelled out. However, it seems unlikely that a larger male sample size would have revealed a main effect for male subjects in the same direction as for female subjects. The results provide evidence for a sex-specific interconnection between the serotonergic and GABAergic systems.

Taken together, the present data provided evidence for a specific molecular mechanism involving the interconnection between the serotonergic and the GABAergic systems in the PFC, which may play important roles in the pathophysiology of highly prevalent psychiatric conditions. Moreover, our results, when combined with previous evidence, suggest that these molecular mechanisms contribute to the sex differences in the epidemiology and clinical characteristics of stress-related psychiatric disorders. 


\section{Acknowledgements}

This research was supported by the Intramural Research Program of the National Institutes of Mental Health. We thank Qiaoping Yuan and Pei-Hong Shen for their support in data management and bioinformatics. Gregor Hasler received honoraria or consulting fees from Lundebck, Servier, Lilly, Bistol-Myers Squibb, GlaxoSmithKline and Astra Zeneca for projects unrelated to this study. Wayne Drevets, M.D. is an employee of Johnson \& Johnson, Inc. and has consulted for Myriad/Rules Based Medicine and Eisai, Inc. for projects unrelated to this study.

\section{Statement of Interest}

None.

\section{References}

Akbarian S, Kim JJ, Potkin SG, Hagman JO, Tafazzoli A, Bunney Jr. WE, Jones EG (1995) Gene expression for glutamic acid decarboxylase is reduced without loss of neurons in prefrontal cortex of schizophrenics. Arch Gen Psychiatry 52:258-266.

Bhagwagar Z, Wylezinska M, Taylor M, Jezzard P, Matthews PM, Cowen PJ (2004) Increased brain GABA concentrations following acute administration of a selective serotonin reuptake inhibitor. Am J Psychiatry 161:368-370.

Booji L, Turecki G, Leyton M, Gravel P, De lara CL, Diksic M, Benkelfat C (2012) Tryptophan hydroxylase (2) gene polymorphisms predict brain serotonin synthesis in the orbitofrontal cortex in humans. Mol Psychiatry 17:809-817.

Brown SM, Peet E, Manuck SB, Williamson DE, Dahl RE, Ferrell RE, Hariri AR (2005) A regulatory variant of the human tryptophan hydroxylase-2 gene biases amygdala reactivity. Mol Psychiatry 10:884-888.

Canli T, Congdon E, Gutknecht L, Constable RT, Lesch KP (2005) Amygdala responsiveness is modulated by tryptophan hydroxylase-2 gene variation. J Neural Transm 112:1479-1485.

Chen GL, Vallender EJ, Miller GM (2008) Functional characterization of the human TPH2 5 ' regulatory region: untranslated region and polymorphisms modulate gene expression in vitro. Hum Genet 122:645-657.

Ciranna L (2006) Serotonin as a modulator of glutamateand GABA-mediated neurotransmission: implications in physiological functions and in pathology. Curr Neuropharmacol 4:101-114.

Clayton AH, Stewart RS, Fayyad R, Clary CM (2006) Sex differences in clinical presentation and response in panic disorder: pooled data from sertraline treatment studies. Arch Women Ment Health 9:151-157.

Cosgrove KP, Mazure CM, Staley JK (2007) Evolving knowledge of sex differences in brain structure, function, and chemistry. Biol Psychiatry 62:847-855.

De Luca V, Mueller DJ, Tharmalingam S, King N, Kennedy JL (2004) Analysis of the novel TPH2 gene in bipolar disorder and suicidality. Mol Psychiatry 9:896-897.

De Luca V, Voineskos D, Wong GWH, Shinkai T, Rothe C, Strauss J, Kennedy JL (2005) Promoter polymorphism of second tryptophan hydroxylase isoform (TPH2) in schizophrenia and suicidality. Psychiatry Res 134:195-198.

Falush D, Stephens M, Pritchard JK (2003) Inference of population structure using multilocus genotype data: linked loci and correlated allele frequencies. Genetics 164:1567-1587.

Fang YR, Zhang C, Li ZZ, Shao Y, Xie B, Du YS, Yu SY (2011) Association study of tryptophan hydroxylase-2 gene in schizophrenia and its clinical features in Chinese Han population. J Mol Neurosci 43:406-411.

Feng J, Cai X, Zhao J, Yan Z (2001) Serotonin receptors modulate GABA(A) receptor channels through activation of anchored protein kinase $\mathrm{C}$ in prefrontal cortical neurons. J Neurosci 21:6502-6511.

Goddard AW, Mason GF, Almai A, Rothman DL, Behar KL, Petroff OAC, Charney DS, Krystal JH (2001) Reductions in occipital cortex GABA levels in panic disorder detected with H-1-magnetic resonance spectroscopy. Arch Gen Psychiatry 58:556-561.

Grant BF, Hasin DS, Stinson FS, Dawson DA, Goldstein RB, Smith S, Huang B, Saha TD (2006) The epidemiology of DSM-IV panic disorder and agoraphobia in the United States: results from the national epidemiologic survey on alcohol and related conditions. J Clin Psychiatry 67:363-374.

Gutknecht L, Jacob C, Strobel A, Kriegebaum C, Müller J, Zeng Y, Markert C, Escher A, Wendland J, Reif A, Mössner R, Gross C, Brocke B, Lesch K-P (2007) Tryptophan hydroxylase-2 gene variation influences personality traits and disorders related to emotional dysregulation. Int J Neuropsychopharmacol 10:309-320.

Gutknecht L, Kriegebaum C, Waider J, Schmitt A, Lesch K-P (2009) Spatio-temporal expression of tryptophan hydroxylase isoforms in murine and human brain: convergent data from Tph2 knockout mice. Eur Neuropsychopharmacol 19:266-282.

Hasler G (2010) Reduced cortical GABA concentration as putative endophenotype in major depression. Biol Psychiatry 67:1-16.

Hasler G, Northoff G (2011) Discovering imaging endophenotypes for major depression. Mol Psychiatry 16:604-619.

Hasler G, van der Veen JW, Tumonis T, Meyers N, Shen J, Drevets WC (2007) Reduced prefrontal glutamate/ glutamine and gamma-aminobutyric acid levels in major depression determined using proton magnetic resonance spectroscopy. Arch Gen Psychiatry 64:193-200.

Hasler G, van der Veen JW, Geraci M, Shen J, Pine D, Drevets WC (2009) Prefrontal cortical gamma-aminobutyric acid levels in panic disorder determined by proton magnetic resonance spectroscopy. Biol Psychiatry 65:273-275. 
Hasler G, van der Veen JW, Grillon C, Drevets WC, Shen J (2010) Effect of acute psychological stress on prefrontal GABA concentration determined by proton magnetic resonance spectroscopy. Am J Psychiatry 167:1226-1231.

Hayes AF, Matthes J (2009) Computational procedures for probing interactions in OLS and logistic regression: SPSS and SAS implementations. Behav Res Methods 41:924-936.

Hodgkinson CA, Yuan QP, Xu K, Shen PH, Heinz E, Lobos EA, Binder EB, Cubells J, Ehlers CL, Gelernter J, Mann J, Riley B, Roy A, Tabakoff B, Todd RD, Zhou ZF, Goldman D (2008) Addictions biology: haplotype-based analysis for 130 candidate genes on a single array. Alcohol Alcohol 43:505-515.

Jackson MF, Esplin B, Capek R (2000) Reversal of the activity-dependent suppression of GABA-mediated inhibition in hippocampal slices from gamma-vinyl GABA (vigabatrin)-pretreated rats. Neuropharmacology 39:65-74.

Jacob C, Nguyen T, Dempfle A, Heine M, Windemuth-Kieselbach C, Baumann K, Jacob F, Prechtl J, Wittlich M, Herrmann M, Gross-Lesch S, Lesch K-P, Reif A (2010) A gene-environment investigation on personality traits in two independent clinical sets of adult patients with personality disorder and attention deficit/hyperactive disorder. Eur Arch Psychiatry Clin Neurosci 260:317-326.

Jacobsen JP, Siesser WB, Sachs BD, Peterson S, Cools MJ, Setola V, Folgering JH, Flik G, Caron MG (2012) Deficient serotonin neurotransmission and depression-like serotonin biomarker alterations in tryptophan hydroxylase 2 (Tph2) loss-of-function mice. Mol Psychiatry 17:694-704.

Kim YK, Lee HJ, Yang JC, Hwang JA, Yoon HK (2009) A tryptophan hydroxylase 2 gene polymorphism is associated with panic disorder. Behav Genet 39:170-175.

Krystal JH, Sanacora G, Blumberg H, Anand A, Charney DS, Marek G, Epperson CN, Goddard A, Mason GF (2002) Glutamate and GABA systems as targets for novel antidepressant and mood-stabilizing treatments. Mol Psychiatry 7:S71-S80.

Li J, Ji L (2005) Adjusting multiple testing in multilocus analyses using the eigenvalues of a correlation matrix. Heredity 95:221-227.

Lim JE, Pinsonneault J, Sadee W, Saffen D (2007) Tryptophan hydroxylase 2 (TPH2) haplotypes predict levels of TPH2 mRNA expression in human pons. Mol Psychiatry 12:491-501.

Lin YM, Chao SC, Chen TM, Lai TJ, Chen JS, Sun HS (2007) Association of functional polymorphisms of the human tryptophan hydroxylase 2 gene with risk for bipolar disorder in Han Chinese. Arch Gen Psychiatry 64:1015-1024.

Maron E, Toru I, Must A, Tasa G, Toover E, Vasar V, Lang A, Shlik J (2007) Association study of tryptophan hydroxylase 2 gene polymorphisms in panic disorder. Neurosci Lett 411:180-184.

Maron E, Toru I, Hirvonen J, Tuominen L, Lumme V, Vasar V, Shlik J, Nutt DJ, Helin S, Nagren K, Tiihonen J, Hietala J (2011) Gender differences in brain serotonin transporter availability in panic disorder. J Psychopharmacol 25:952-959.
Mossner R, Freitag CM, Gutknecht L, Reif A, Tauber R, Franke P, Fritze J, Wagner G, Peikert G, Wenda B, Sand P, Rietschel M, Garritsen H, Jacob C, Lesch KP, Deckert J (2006a) The novel brain-specific tryptophan hydroxytase-2 gene in panic disorder. J Psychopharmacol 20:547-552.

Mossner R, Walitza S, Geller F, Scherag A, Gutknecht L, Jacob C, Bogusch L, Remschmidt H, Simons M, Herpertz-Dahlmann B, Fleischhaker C, Schulz E, Warnke A, Hinney A, Wewetzer C, Lesch KP (2006b) Transmission disequilibrium of polymorphic variants in the tryptophan hydroxylase-2 gene in children and adolescents with obsessive-compulsive disorder. Int J

Neuropsychopharmacol 9:437-442.

Mouri K, Hishimoto A, Fukutake M, Shiroiwa K, Asano M, Nagasaki Y, Ueno Y, Shirakawa O, Nishiguchi N, Maeda K (2009) TPH2 is not a susceptibility gene for suicide in Japanese population. Prog Neuropsychopharmacol Biol Psychiatry 33:1546-1550.

Must A, Tasa G, Lang A, Vasar E, Koks S, Maron E, Vaeli M (2009) Variation in tryptophan hydroxylase-2 gene is not associated to male completed suicide in Estonian population. Neurosci Lett 453:112-114.

Nyholt DR (2004) A simple correction for multiple testing for single-nucleotide polymorphisms in linkage disequilibrium with each other. Am J Hum Genet 74:765-769.

Perez-Rodriguez MM, Weinstein S, New AS, Bevilacqua L, Yuan Q, Zhou Z, Hodgkinson C, Goodman M, Koenigsberg HW, Goldman D, Siever LJ (2010) Tryptophan-hydroxylase 2 haplotype association with borderline personality disorder and aggression in a sample of patients with personality disorders and healthy controls. J Psychiatr Res 44:1075-1081.

Phelps EA, Delgado MR, Nearing KI, LeDoux JE (2004) Extinction learning in humans: role of the amygdala and vmPFC. Neuron 43:897-905.

Puig MV, Artigas F, Celada P (2005) Modulation of the activity of pyramidal neurons in rat prefrontal cortex by raphe stimulation in vivo: involvement of serotonin and GABA. Cereb Cortex 15:1-14.

Quirk GJ, Likhtik E, Pelletier JG, Pare D (2003) Stimulation of medial prefrontal cortex decreases the responsiveness of central amygdala output neurons. J Neurosci 23:8800-8807.

Reuter M, Kuepper Y, Hennig J (2007) Association between a polymorphism in the promoter region of the TPH2 gene and the personality trait of harm avoidance. Int J Neuropsychopharmacol 10:401-404.

Roche S, McKeon P (2009) Support for tryptophan hydroxylase-2 as a susceptibility gene for bipolar affective disorder. Psychiatr Genet 19:142-146.

Sailasuta N, LeRoux P, Hurd R, Wang P, Sachs N, Ketter T (2001) Detection of cerebral gamma-aminobutyric acid (GABA) in bipolar disorder patients and healthy volunteers at 3T. Proc Intl Soc Mag Reson Med 9:1011.

Sanacora G, Mason GF, Rothman DL, Behar KL, Hyder F, Petroff OA, Berman RM, Charney DS, Krystal JH (1999) Reduced cortical gamma-aminobutyric acid levels in 
depressed patients determined by proton magnetic resonance spectroscopy. Arch Gen Psychiatry 56:1043-1047.

Sanacora G, Mason GF, Rothman DL, Hyder F, Ciarcia JJ, Ostroff RB, Berman RM, Krystal JH (2003) Increased cortical GABA concentrations in depressed patients receiving ECT. Am J Psychiatry 160:577-579.

Shen J, Rothman DL, Brown P (2002) In vivo GABA editing using a novel doubly selective multiple quantum filter. Magn Reson Med 47:447-454.

Šidák Z (1967) Rectangular confidence regions for the means of multivariate normal distributions. J Am Stat Assoc 62:626.

Smiley JF, Goldman-Rakic PS (1996) Serotonergic axons in monkey prefrontal cerebral cortex synapse predominantly on interneurons as demonstrated by serial section electron microscopy. J Comp Neurol 367:431-443.

Sotres-Bayon F, Quirk GJ (2010) Prefrontal control of fear: more than just extinction. Curr Opin Neurobiol 20:231-235.

Waider J, Araragi N, Gutknecht L, Lesch KP (2011)

Tryptophan hydroxylase-2 (TPH2) in disorders of cognitive control and emotion regulation: a perspective.

Psychoneuroendocrinology 36:393-405.

Waider J, Proft F, Langlhofer G, Asan E, Lesch K-P, Gutknecht L (2012) GABA concentration and GABAergic neuron populations in limbic areas are differentially altered by brain serotonin deficiency in Tph2 knockout mice. Histochem Cell Biol 139:267-281.

Walitza S, Renner TJ, Dempfle A, Konrad K, Wewetzer C, Halbach A, Herpertz-Dahlmann B, Remschmidt H, Smidt J, Linder M, Flierl L, Knolker U, Friedel S, Schafer H, Gross C,
Hebebrand J, Warnke A, Lesch KP (2005) Transmission disequilibrium of polymorphic variants in the tryptophan hydroxylase-2 gene in attention-deficit/hyperactivity disorder. Mol Psychiatry 10:1126-1132.

Weissman MM, Bland RC, Canino GJ, Faravelli C, Greenwald S, Hwu H-G, Joyce PR, Karam EG, Lee C-K, Lellouch J, Lepine J-P, Newman SC, Oakley-Browne MA, Rubio-Stipec M, Wells JE, Wickramaratne PJ, Wittchen H-U, Yeh E-K (1997) The cross-national epidemiology of panic disorder. Arch Gen Psychiatry 54:305-309.

Wyss M, Kaddurah-Daouk R (2000) Creatine and creatinine metabolism. Physiol Rev 80:1107-1213.

Yoon H-K, Kim Y-K (2009) TPH2 -703G/T SNP may have important effect on susceptibility to suicidal behavior in major depression. Prog Neuropsychopharmacol Biol Psychiatry 33:403-409.

Zhong P, Yan Z (2011) Differential regulation of the excitability of prefrontal cortical fast-spiking interneurons and pyramidal neurons by serotonin and fluoxetine. PLoS ONE 6:e16970.

Zhou N, Wang L (2008) Perfect population classification on Hapmap data with a small number of SNPs. In: Neural information processing, Part II, vol. 4985 (Ishikawa M. et al., eds), pp. 789-797. Berlin: Springer-Verlag.

Zhou ZF, Roy A, Lipsky R, Kuchipudi K, Zhu GS, Taubman J, Enoch MA, Virkkunen M, Goldman D (2005) Haplotype-based linkage of tryptophan hydroxylase 2 to suicide attempt, major depression, and cerebrospinal fluid 5-hydroxyindoleacetic acid in 4 populations. Arch Gen Psychiatry 62:1109-1118. 